\title{
22 HIGH BLOOD LEAD LEVELS IN E-WASTE RECYCLERS
}

Ashish Mittal, Mohini Malviya, J John OHS-MCS, New Delhi, India

10.1136/oemed-2011-100382.22

Objectives There is a huge informal sector of electronic and electrical waste recycling in India. Domestic as well as imported e-waste is being recycled to extract valuable heavy metals like lead, cadmium, chromium, mercury, aluminium, and gold. Workers are exposed to toxic fumes through inhalation and skin contact in the poor working conditions.

Methods Blood samples of 20 workers (13 male, 5 female and 2 children) were taken randomly from 64 workers involved in the process of de-soldering of components and burning of printed circuit boards to recover the metals. Blood samples were analysed for blood lead levels, haemogram and renal function tests.

Results All the 20 samples analysed for blood lead levels were found to be high of prescribed levels of $10 \mu \mathrm{g} / \mathrm{dl}$ of CDC. The lowest BLL was 18.3 and highest was $40.4 \mu \mathrm{g} / \mathrm{dl}$, with an average level of blood lead $30.13 \mu \mathrm{g} / \mathrm{dl}$ in these 20 workers. The minimum age of workers being 14 years and maximum 45 years (mean age 30 years), No evidence of haemato-toxicity or renal toxicity or neurotoxicity could be found with $1-3$ years 


\section{Abstracts}

of exposure to recycling of e-waste. None of the workers uses any personal protective equipment.

Conclusions The high blood lead levels, especially in the children will have long term health effects on these workers. Long term follow ups for evaluation of toxicity from other metals must be done. Improvement of working condition, prohibiting child labour and technological interventions for the recovery of toxic heavy metals are required immediately. 